\title{
NUMERICAL MODELING OF HYDRODYNAMIC AND SEDIMENT SILTATION DUE TO TYPHOON IN ESTUARY CHANNEL REGULATION
}

\author{
Hongbo Zhao ${ }^{\mathrm{a}, \mathrm{b}}$ \\ Qinghe Zhang ${ }^{\mathrm{a}}$ \\ Mingxiao Xie $\mathrm{Xi}^{\mathrm{b}}$ \\ a) School of Civil Engineering, Tianjin University, Tianjin, China \\ b) Tianjin Research Institute for Water Transport Engineering \\ Key Laboratory of EngineeringSediment of Ministry of Transport \\ Tianjin, China
}

\begin{abstract}
Oujiang Estuary is a complex tidal estuary with many channels and shoals in the East China Sea, which was affected by typhoon frequently. The navigation channel of Wenzhou Port is located in the north branch of Oujiang Estuary, which happened serious sediment siltation in many times due to typhoon impact. The regulation is considered to decrease siltaion of the channel and protect shoals as well. According to the site survey data, the mathematic model is established and validated, which simulates the hydrodynamic, sediment transport and channel siltation due to typhoon in Oujiang Estuary. The channel regulation scenario is studied by the model simulation after analysis of the silation character. It indicates that the high concentration sediment from shoals north of channel is main sediment source caused siltation in the channel, which can be prevented into the channel by the regulation scenario and decrease siltation efficiently.
\end{abstract}

Keywords: Oujiang Estuary, numerical model, channel regulation, sediment siltation, typhoon

\section{INTRODUCTION}

There are over 3 times typhoon influenced seriously and 1.4 times typhoon landed directly in average annually in east sea areas of Zhejiang Province, China, according to the statistics. During typhoon attacking, storm surge and wave is generated driven by strong wind, which enhances the water turbulence. The sediment on of nearshore area and estuary is suspended and transported by strong wave and storm surge, which may cause serious siltation in harbor and navigation channel. Sudden siltation due to typhoon in Yangtze Estuary navigation channels had affect the operation and development of Shanghai International Shipping Center, which caused the siltation thickness about $0.3 \sim 0.7 \mathrm{~m}$ in each typhoon [6]. Oujiang Estuary is a very complex tidal estuary with many channels and shoals in the East China Sea, which was affected by typhoon frequently. The navigation channel of Wenzhou Port is located in the north branch of Oujiang Estuary, which happened serious sediment siltation in many times due to typhoon impact. Therefore, it is important and necessary to study the hydrodynamics and sediment siltaion of the channel due to typhoon, which is not only helpful to learn mechanism of siltation but also provide the basis for the channel regulation. Numerical model can be used to simulate the typhoon, wind wave, current and sediment sitation. A set of models will be established to study the sediment siltation due to typhoon in estuary channel regulation in this paper.

\section{NATURAL CONDITIONS AND SILTATION}

Oujiang is a strong tidal estuary that tides can reach up to 78 $\mathrm{km}$ upstream form its mouth, with a river basin of $1.8 \times 10^{4} \mathrm{~km}^{2}$. According to measured data, the average total amount of fresh water discharge is $470 \mathrm{~m}^{3} / \mathrm{s}$, and the suspend load transport amount is about $2.051 \times 10^{6} \mathrm{t}$ annually. Oujiang Estuary is divide North branch and South branch by Lingkun island and Niyu island. The average water diversion ratios of the South Branch and the North Branch of the Oujiang River are $21 \%$ and $79 \%$ during flood, and $26 \%$ and $74 \%$ during ebb [3]. Oujiang estuary is dominated by semidiurnal tides with average tidal range of over $4 \mathrm{~m}$ and the maximum tidal range of over $7 \mathrm{~m}$. Tidal currents in the estuary belong to shallow water semidiurnal tidal currents. The maximum current velocity in the north channel is about $2.0 \sim 3.0 \mathrm{~m} / \mathrm{s}$. The sediment concentration is high near the estuary and the shoals where the maximum vertically averaged concentration measured were all over 1.0 $\mathrm{kg} / \mathrm{m}^{3}$. The sediment concentration impact of typhoon is higher than normal hydrodynamic conditions. The average median 
size $\mathrm{d}_{50}$ of suspended load in the Oujiang Estuary is range from $6 \times 10^{-6} \mathrm{~m}$ to $8 \times 10^{-6} \mathrm{~m}$.

The navigation channel of Wenzhou Port is located in the north branch of Oujiang estrary (Fig.1), which already caused serious sediment siltation near Sanjiaosha shoals while typhoon affected. According to the measured data in 2005, the siltation thickness is above $0.4 \mathrm{~m}$ averagely in the channel near the shoals due to typhoon Haitang. The mean siltaion thickness is $1.1 \mathrm{~m}$ and $1.2 \mathrm{~m}$ influenced by typhoon Matsa and typhoon Talim respectively [7]. The depth change measured in the channel near shoals is shown in Fig. 2.

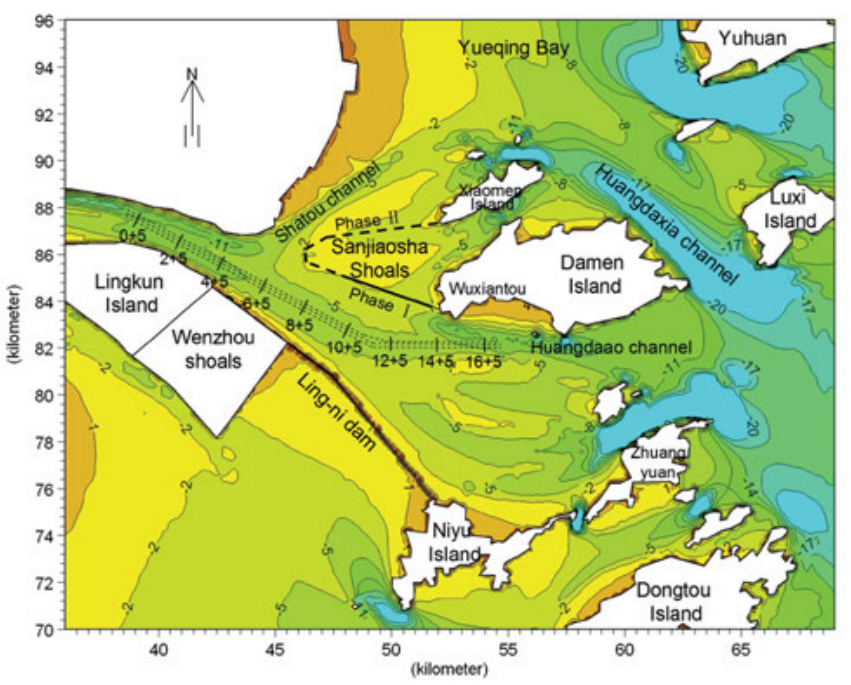

Fig. 1. Sketch of Oujiang Estuary and layout of the channel regulation

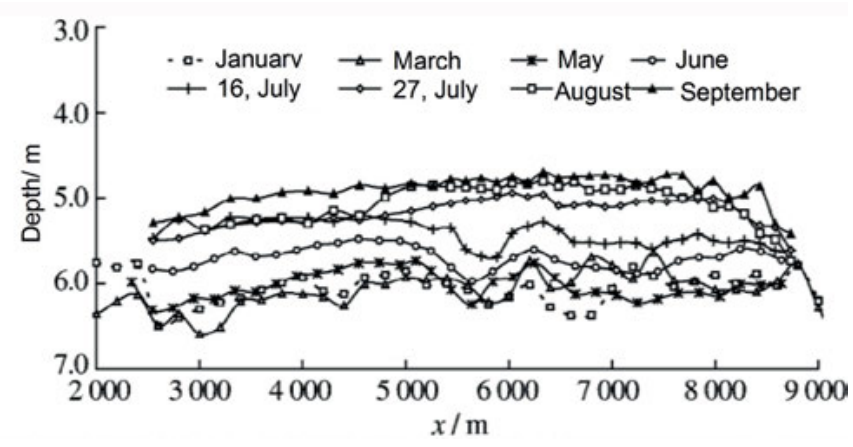

Fig. 2. The depth measured along the channel near Sanjiaosha shoals in 2005

The hydrodynamic and sediment conditions of Oujiang Estuary are very complex, and the typhoon is important hydrodynamic factor of sudden serious siltation in channel. The sediment suspended and transported under storm wave from Sanjiaosha shoals is the main sediment source caused serious silation in the channel. In order to reduce the channel siltation, the regulation is considered in north of channel shown in Fig. 1, and the channel is deepened to $-7 \mathrm{~m}$ (refer to theoretical sea level datum, the same below). The regulation dam level is $+3.7 \mathrm{~m}$ for Scenario $2 \mathrm{a}$ and $+6.8 \mathrm{~m}$ for Scenario $2 \mathrm{~b}$.

The numerical models are established to study the effect of reduced siltation due to typhoon in different regulation scenario.

\section{MODEL DESCRIPTION}

Based on characteristic of hydrodynamics and sediment of Oujiang Estuary, the typhoon wind model, hydrodynamic and sediment transport model is considered that will be applied to simulate the storm wave and surge, current, sediment transport and sudden siltation in the channel due to typhoon. The numerical model composition is shown in Fig.3.

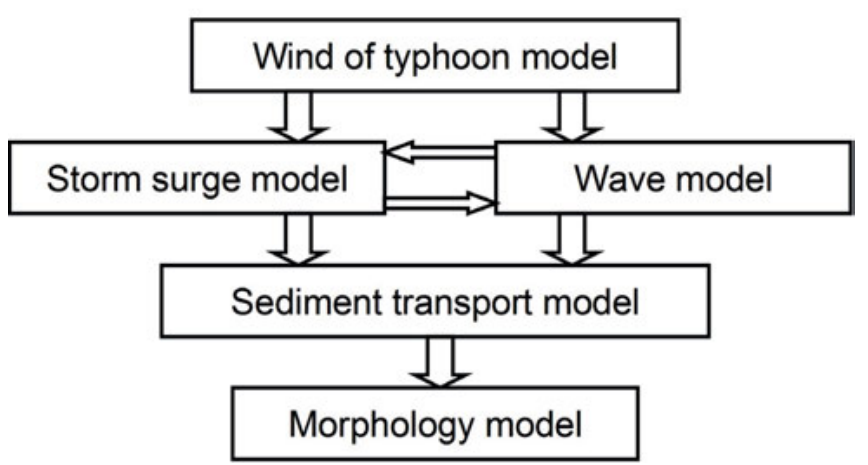

Fig. 3. Composition of the numerical model

\section{WIND OF TYPHOON MODEL}

Parametric wind models are frequently used for the wind forcing recent years. The advantages of parametric models are their convenience of use and the fact that it can reproduce the atmospheric pressure and wind distribution characteristic of tropical cyclone [2]. The models can be used to study the sensitivity of surge to changes of track, central atmospheric pressure, radius of maximum wind velocity, and other parameters.

The model equations of atmospheric pressure field due to typhoon are as follows:

$$
\begin{array}{cl}
P(r)=P_{\infty}-\frac{P_{\infty}-P_{0}}{\sqrt{1+2(r / R)^{2}}} & (0 \leq r \leq 2 R) \\
P(r)=P_{\infty}-\frac{P_{\infty}-P_{0}}{1+r / R} & (2 R \leq r<\infty)
\end{array}
$$

where $\mathrm{P}_{(\mathrm{r})}$ is atmospheric pressure at the calculating point, $\mathrm{P}_{0}$ is atmospheric pressure at the center of typhoon, $\mathrm{p}_{\infty}$ is the peripheral atmospheric pressure, $\mathrm{R}$ is radius of maximum wind velocity, $\mathrm{r}$ is the distance from the calculating point to the center of typhoon.

The model equations of wind due to typhoon are as follows [5]:

$$
\begin{aligned}
(0 \leq r \leq 2 R) & \\
W_{x}=C_{1} V_{d x} \exp \left(-\frac{\pi}{4} \cdot \frac{|r-R|}{R}\right)-C_{2}\{ & \left.-\frac{f}{2}+\sqrt{\frac{f^{2}}{4}+\frac{2 \Delta P}{\rho_{a} R^{2}}\left[1+2\left(\frac{r}{R}\right)^{2}\right]^{-\frac{3}{2}}}\right\} \\
& {\left[\left(x-x_{0}\right) \sin \theta+\left(y-y_{0}\right) \cos \theta\right] } \\
W_{y}=C_{1} V_{d y} \exp \left(-\frac{\pi}{4} \cdot \frac{|r-R|}{R}\right)+C_{2}\{ & \left\{\frac{f}{2}+\sqrt{\frac{f^{2}}{4}+\frac{2 \Delta P}{\rho_{a} R^{2}}\left[1+2\left(\frac{r}{R}\right)^{2}\right]^{-\frac{3}{2}}}\right\} \\
& \cdot\left[\left(x-x_{0}\right) \cos \theta-\left(y-y_{0}\right) \sin \theta\right]
\end{aligned}
$$




$$
(2 R \leq r<\infty)
$$

$$
\begin{array}{r}
W_{x}=C_{1} V_{d x} \exp \left(-\frac{\pi}{4} \cdot \frac{|r-R|}{R}\right)-C_{2}\left\{-\frac{f}{2}+\sqrt{\frac{f^{2}}{4}+\frac{\Delta P}{\rho_{a} R^{2}}\left[1+\frac{r}{R}\right]^{-2}}\right\} \\
\cdot\left[\left(x-x_{0}\right) \sin \theta+\left(y-y_{0}\right) \cos \theta\right] \\
W_{y}=C_{1} V_{d y} \exp \left(-\frac{\pi}{4} \cdot \frac{|r-R|}{R}\right)+C_{2}\left\{-\frac{f}{2}+\sqrt{\frac{f^{2}}{4}+\frac{\Delta P}{\rho_{a} R r}\left[1+\frac{r}{R}\right]^{-2}}\right\} \\
\cdot\left[\left(x-x_{0}\right) \cos \theta-\left(y-y_{0}\right) \sin \theta\right]
\end{array}
$$

where $\mathrm{W}_{\mathrm{x}}, \mathrm{W}_{\mathrm{y}}$ is wind velocity in $\mathrm{x}, \mathrm{y}$ direction at the calculating point, $\mathrm{C}_{1}, \mathrm{C}_{2}$ is empirical constant $\left(\mathrm{C}_{1}=0.1, \mathrm{C}_{2}=0.8\right)$, $\mathrm{V}_{\mathrm{dx}}, \mathrm{V}_{\mathrm{dy}}$ is the movement velocity of typhoon in $\mathrm{x}, \mathrm{y}$ direction, $f$ is the Coriolis force parameter, $\mathrm{x}_{0}, \mathrm{y}_{0}$ is the coordinate of the center of typhoon, $\theta$ is the flow angle $\left(\theta=20^{\circ}\right), \rho_{\mathrm{a}}$ is atmospheric density, $\Delta \mathrm{p}=\mathrm{p}_{\infty}-\mathrm{p}_{0}$.

The atmospheric pressure at the center of typhoon $\left(\mathrm{p}_{0}\right)$ and the radius of maximum wind velocity $(\mathrm{R})$ observed by an aerial survey form $28^{\circ} \mathrm{N}$ to $31^{\circ} \mathrm{N}$ in the northwestern Pacific was extracted to construct the following approximate relationship [4]:

$$
R=R_{k}-0.4\left(P_{0}-900\right)+0.01\left(P_{0}-900\right)^{2}
$$

in which, $\mathrm{R}_{\mathrm{k}}$ is an experimental constant. The recommended value is 40 , and it can be adjusted according to the validated precision of the atmospheric pressure and wind velocity measured.

\section{WAVE MODEL}

It is very important to simulate wave process for describing sediment movement. The SWAN wave model is typically designed for wave simulations in the near-shore region and applied in many coastal engineering recent years. The SWAN model is a third generation spectral model, suitable for the simulation of wind generated waves from the nearshore to the surf-zone. The spectrum that is considered in SWAN is the action density spectrum rather than the energy density spectrum. In the SWAN wave model, the evolution of the wave spectrum and time is described by the spectral action balance equation, which for Cartesian coordinates is:

$$
\frac{\partial}{\partial t} N+\frac{\partial}{\partial x} C_{x} N+\frac{\partial}{\partial y} C_{y} N+\frac{\partial}{\partial \sigma} C_{\sigma} N+\frac{\partial}{\partial \theta} C_{\theta} N=\frac{S}{\sigma}
$$

The first term in the left-hand side of this equation represents the local rate of change of action density in time; the second and third terms represent propagation of action in geographical space (with propagation velocities $\mathrm{C}_{\mathrm{x}}$ and $\mathrm{C}_{\mathrm{y}}$ in $\mathrm{x}$ and $\mathrm{y}$ space). The fourth term represents a shifting of the relative frequency due to variations in depths and currents (with propagation velocity $\mathrm{C}_{\sigma}$ in $\boldsymbol{\sigma}$ space). The fifth term represents depth-induced and current-induced refraction and propagation in directional space (with propagation velocity $\mathrm{C}_{\theta}$ in $\theta$ space). The term $S=S(\sigma, \theta)$ at the right hand side of the action balance equation is the source term in terms of energy density, representing the effects of generation, dissipation and nonlinear wave-wave interaction. This term consists of linear and exponential growth by wind, dissipation due to white capping, bottom friction, depth-induced wave breaking and energy transfer due to quadruplet and triad wave-wave interaction.

\section{STORM SURGE MODEL}

To simulate the storm surge, the Advanced Circulation Model (ADCIRC) is adopted, which can simulate tide and current over an unstructured grid. It can also be used for simulation the storm surge driven by wind and wave in coastal waters; forecasting hurricane storm surge and flooding. It can also take into account of influence of wave radiation stress that is important to current and sediment movement. The governing equation of is described as follows:

$$
\begin{gathered}
\frac{\partial \zeta}{\partial t}+\frac{\partial U H}{\partial x}+\frac{\partial V H}{\partial y}=0 \\
\frac{\partial U}{\partial t}+U \frac{\partial U}{\partial x}+V \frac{\partial U}{\partial y}-f V=-\frac{\partial}{\partial x}\left[\frac{p_{\zeta}}{\rho_{0}}+g \zeta-g(\eta+\gamma)\right] \\
+\frac{\tau_{\zeta x}}{\rho_{0} H}-\frac{\tau_{b x}}{\rho_{0} H}+D_{x}-B_{x} \\
\frac{\partial V}{\partial t}+U \frac{\partial V}{\partial x}+V \frac{\partial V}{\partial y}-f U=-\frac{\partial}{\partial y}\left[\frac{p_{\zeta}}{\rho_{0}}+g \zeta-g(\eta+\gamma)\right] \\
+\frac{\tau_{\zeta y}}{\rho_{0} H}-\frac{\tau_{b y}}{\rho_{0} H}+D_{y}-B_{y}
\end{gathered}
$$

where, $\mathrm{U}$ and $\mathrm{V}$ are depth-averaged velocities in the $\mathrm{x}, \mathrm{y}$ directions, $\zeta$ is free surface departure from the geoid, $\mathrm{p}_{\mathrm{s}}$ is total water column thickness, is the Coriolis force parameter, is atmospheric pressure of water surface, $\rho_{0}$ is water density, $\tau_{s x}$ and $\tau_{s y}$ is the imposed surface stress, $\tau_{b x}$ and $\tau_{b y}$ is the bottom stress, $\mathrm{D}_{\mathrm{x}}$ and $\mathrm{D}_{\mathrm{y}}$ are momentum dispersions, $\mathrm{B}_{\mathrm{x}}$ and $\mathrm{B}_{\mathrm{y}}$ are vertically integrated baroclinic pressure gradient, $(\eta+\gamma)$ is Newtonian equilibrium tide potential.

\section{SEDIMENT TRANSPORT MODEL}

Sediment transport is adopted sediment carrying capacity model to simulate, which has been successfully in many sediment transport prediction with good results for both cohesive sediments and non-cohesive sediments in coastal area in China [1]. The suspended sediment transport equation can be written as:

$$
\frac{\partial(h S)}{\partial t}+\frac{\partial(h u S)}{\partial x}+\frac{\partial(h v S)}{\partial y}+\alpha \omega\left(S-S_{*}\right)=0
$$

In which, $\mathrm{h}$ is water depth, $\mathrm{S}$ is the depth-averaged sediment concentration, $S_{*}$ is the sediment carrying capacity for the combined waves and current, $u$ and $v$ are the current velocity along $\mathrm{x}$ and $\mathrm{y}$ directions, respectively, $\alpha$ is the deposition probability, $\omega$ is the settling velocity, $S_{*}$ is the sediment carrying capacity, which can be applied to combined wave and current situations. It is expressed as

$$
S_{*}=S_{*_{C}}+S_{*_{W}}
$$


In which $S_{{ }^{*} \mathrm{C}}$ and $\mathrm{S}_{* \mathrm{~W}}$ are the sediment carrying capacities due current and waves, repetitively.

The carrying capacity of pure current can be expressed as follows:

$$
S_{*_{C}}=\alpha \frac{\gamma \gamma_{s}}{\left(\gamma_{s}-\gamma\right)} \frac{V^{3}}{c^{2} h \omega}
$$

In which $\alpha$ is a dimensionless coefficient to be determined by experimental or in-situ data, $\mathrm{V}$ is the current velocity. The carrying capacity of waves can be expressed as following:

$$
S_{* W}=\beta_{1} \frac{\gamma \gamma_{s}}{\gamma_{s}-\gamma} \frac{f_{w} H_{r m s}^{3}}{T^{3} g^{2} h \omega \sinh ^{3}(k h)}+\beta_{2} \frac{\gamma_{s}}{\gamma_{s}-\gamma} \frac{D_{B 2}}{g h \omega}
$$

where $f_{\mathrm{w}}$ is the friction factor, $\mathrm{H}_{\mathrm{rms}}$ is the root-mean-square wave height, $T$ is the wave period, $k$ is the wave number, $D_{B 2}$ is wave energy dissipation, $\beta_{1}$ is dimensionless coefficient, $\beta_{2}$ is dimensionless coefficient in breaking wave condition.

\section{MORPHOLOGY MODEL}

The seabed change caused by suspended sediment equation can be expressed as follows:

$$
\gamma_{0} \frac{\partial \eta_{s}}{\partial t}=\alpha \omega\left(S-S_{*}\right)
$$

where $\eta_{\mathrm{s}}$ is the seabed elevation induced by suspended sediment, $\gamma_{0}$ is the dry density of suspended sediment, $\alpha$ is the deposition probability, which can be adjusted according to the data measured.

The seabed change caused by bed load sediment equation can be expressed as follows:

$$
\gamma_{b} \frac{\partial \eta_{b}}{\partial t}+\frac{\partial q_{x}}{\partial x}+\frac{\partial q_{y}}{\partial y}=0
$$

where $\eta_{\mathrm{b}}$ is the seabed elevation induced by bed load sediment, $\gamma_{\mathrm{b}}$ is the dry density of bed load sediment, $\mathrm{q}_{\mathrm{x}}$ and $\mathrm{q}_{\mathrm{y}}$ is the components of $\mathrm{q}_{\mathrm{b}}$ in $\mathrm{x}$ and $\mathrm{y}$ directions. $\mathrm{q}_{\mathrm{b}}$ is the bed load transport quantity that can be calculated by the following formula.

$$
q_{b}=\frac{k_{2}}{C_{0}^{2}} \frac{\gamma \gamma_{s}}{\gamma_{s}-\gamma} m \frac{\left|\vec{V}+\vec{V}_{w}\right|^{3 / 2}}{\omega_{b}}
$$

The total erosion and deposition thickness is $\eta_{\mathrm{s}}+\eta_{\mathrm{b}}$.

There are a few important parameters in the model as follows. Manning roughness coefficient $\eta$ is 0.01 ; the dry density of suspended sediment $\gamma_{0}$ is $720 \mathrm{~kg} / \mathrm{m}^{3}$; the settling velocity $\omega$ is $0.0004 \mathrm{~m} / \mathrm{s}$; the sediment carrying capacity, $\beta_{c}$, $\beta_{1}$ and $\beta_{2}$ is $0.0069,0.3$, and $5 \times 10^{-7}$ respectively.

In the process of numerical model above, the wind field is calculated by the Typhoon wind model, and the storm surge and wave field are computed by the ADCIRC and SWAN respectively according to typhoon wind field. The two models take into account of interaction of currents and waves through coupling calculations. The ADCIRC computes the water levels and current velocity field for SWAN, and SWAN feedbacks the radiation stress to ADCIRC. The all factors from results of ADCIRC and SWAN provides to the Sediment transport model for simulation of sediment field. At last, the change of seabed is obtained by the Morphology model.

\section{MODEL VALIDATION}

\section{COMPUTATION DOMAIN AND MODEL GRID}

Typhoon is large scale simulation, but sediment is regional area. The numerical model will adopt the nest method to simulate the hydrodynamic and sediment accurately. The typhoon wind model and wave model adopts the square grid and space step is $5 \mathrm{~km}$, which contains part of South China Sea, Eastern China sea, Yellow sea and Bohai Sea. In the Oujiang Estuary sea areas, the nested grid space step is $100 \mathrm{~m}$. The storm surge model and sediment transport model is established used finite element that the maximum space step is $1500 \mathrm{~m}$ and the minimum is $30 \mathrm{~m}$ (Fig. 4). The west boundary reaches Meiao, and the east boundary reaches $-30 \mathrm{~m}$ contour. The north boundary reaches the Yueqing Bay, and the south boundary reaches north of Aojiang Estuary.

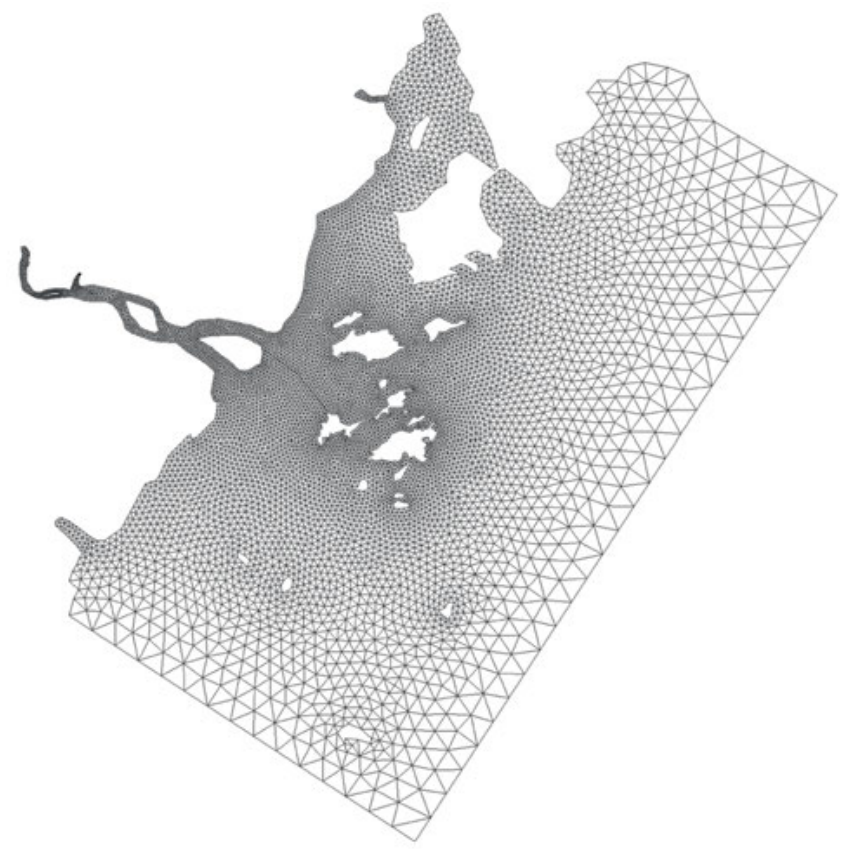

Fig. 4. Grid of regional model

\section{MODEL VERIFICATION}

The typhoon No. 0505 (Haitang) landed at Lianjiang on July 19, 2005, and weakened to a tropical storm as it moved in Nanping, Fujian province. The lowest pressure center is 975 hpa and the maximum wind speed is $32 \mathrm{~m} / \mathrm{s}$. The typhoon path of No.0505 is shown in Tab.1. The discharge of Oujiang River is $4950 \mathrm{~m}^{3} / \mathrm{s}$ measured in the period of typhoon. The siltation thickness is above $0.4 \mathrm{~m}$ averagely in the channel near the Sanjiaosha shoals due to the typhoon.

According to the data of typhoon No.0505, center pressure, the typhoon wind and wave is simulated (Fig.6). The storm surge is simulated using the data of typhoon wind and wave, which tide open boundary is provided by China Tide Model. The sediment transport and siltaion is simulated with the hydrodynamic results above. The validation results of wind 
speed, wave hight, storm surge and siltation thickness in the channel of Oujiang Estuary due to No. 0505 typhoon are shown in Fig.7 Fig.9.

Tab. 1. The track of typhoon No.0505

\begin{tabular}{lccc}
\hline \multicolumn{3}{c}{ Time (UTC) } & \multicolumn{3}{c}{ Latitude $\left({ }^{\circ}\right)$ Longtitude $\left(^{\circ}\right)$ Pressure $(\mathrm{hPa})$} \\
\hline $20057170: 00$ & 21.5 & 125.8 & 920 \\
$20057176: 00$ & 22.3 & 125.0 & 930 \\
$200571712: 00$ & 23.1 & 124.0 & 935 \\
$200571718: 00$ & 23.7 & 123.1 & 940 \\
$20057180: 00$ & 23.8 & 121.8 & 950 \\
$20057186: 00$ & 24.0 & 121.5 & 960 \\
$200571812: 00$ & 24.5 & 121.2 & 970 \\
$200571818: 00$ & 24.8 & 120.6 & 975 \\
$20057190: 00$ & 25.0 & 120.4 & 980 \\
$20057196: 00$ & 25.6 & 120.1 & 980 \\
\hline
\end{tabular}

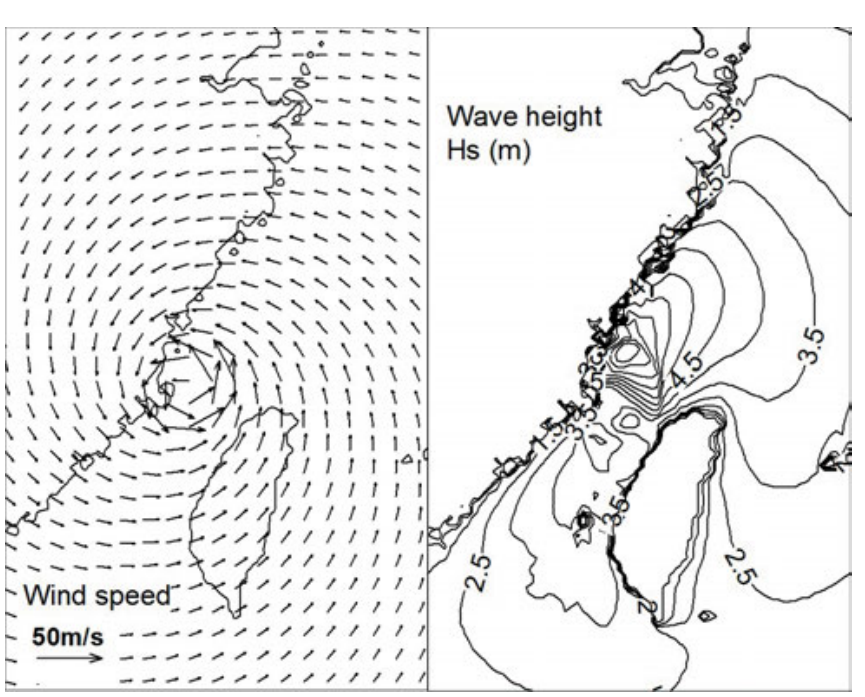

Fig. 6. Wind and wave field of No. 0505 typhoon landing
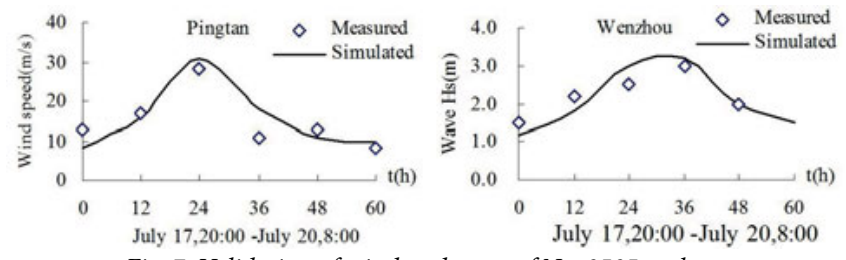

Fig. 7. Validation of wind and wave of No. 0505 typhoon

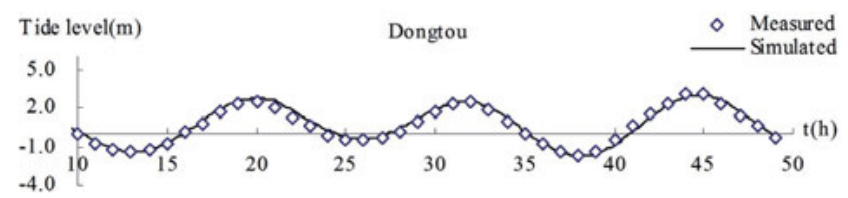

Fig. 8. Validation of storm surge of No. 0505 typhoon

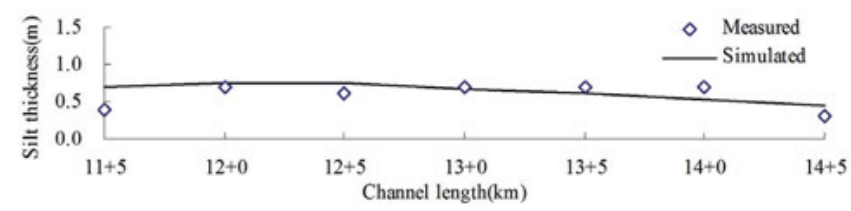

Fig. 8. Validation of storm surge of No. 0505 typhoon
The validation results indicate that the wind speed, storm surge and siltation are in good agreement with the data measured. Moreover, the numerical model also validates the wind speed, storm surge of typhoon No. 9417, No. 9608, and No. 0216. The numerical models can be used to simulate and study on the regulation of channel further.

\section{ANALYSIS OF MODEL RESULTS}

The model simulation result show that the sediment concentration is high that is above $5 \mathrm{~kg} / \mathrm{m}^{3}$ in the Oujiang estuary within the typhoon No. 0505 landing. The sediment concentration of Wenzhou navigation channel is affected by the sediment transported from Sanjiao shoals that is little influence to the north area. Thus, the regulation to reduce the sediment from Sanjiao shoals into the channel should be considered.

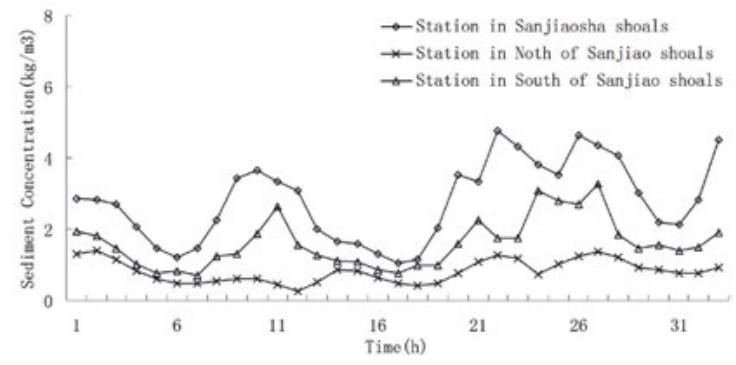

Fig. 10. The sediment concentration in different stations near the Sanjiao shoals due to typhoon No. 0505

The regulation scenarios including dam level of $+3.7 \mathrm{~m}$ and $+6.8 \mathrm{~m}$ is simulated respectively using the numerical model above. According to the results of storm current, sediment concentration and the silation, the sediment concentration in the Sanjiaosha shoals area is $3 \sim 5 \mathrm{~kg} / \mathrm{m}^{3}$ and the high concentration sediment is transported into the channel by ebb tidal current. In the regulation scenarios, the high concentration sediment from Sanjiaosha shoals north of channel is prevented into the channel by the regulation dam, which reduces the silation in channel near the shoals. Figure 11 indicates the current field in flood tide and ebb tide of Scenario $2 b$.

The effect of reduced siltation with regulation is different in the two scenarios, and the siltation volume is decreased with the increase of regulation dam height. Comparing with the channel silation due to typhoon No. 0505 before regulation, the siltation thickness from $5+5 \mathrm{~km}$ to $15+5 \mathrm{~km}$ along the channel near Sanjiaosha shoals of the Scenario 2a (the dam top level $+3.7 \mathrm{~m}$ ) is reduced $26 \%$, and that of Scenario $2 \mathrm{~b}$ (the dam top level $+6.8 \mathrm{~m}$ ) is reduced $47 \%$. The siltation thickness along the channel in different Scenario is shown in Figure 12.

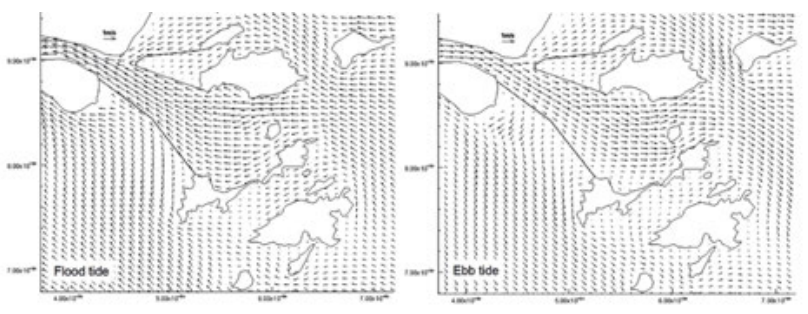

Fig. 11. The flood and ebb tidal current field due to typhoon No.0505 in Scenario $2 b$ 


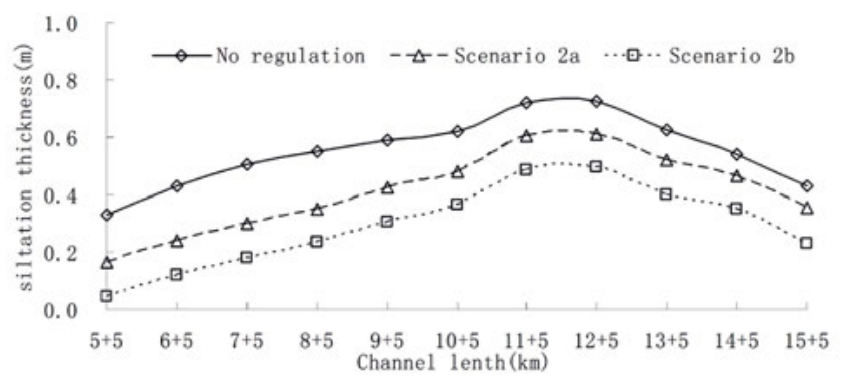

Fig. 12. The siltation thickness due to typhoon No.0505 along channel in different scenarios

\section{CONCLUSIONS}

Based on lots of measured data, the numerical models including typhoon wind model, wave model, storm model and sediment model are established and validated. The simulated results are in good agreement with the data measured. It shows that the high concentration sediment from Sanjiaosha shoals north of channel is main sediment source caused siltation in the channel. The regulation scenarios have good effect to decrease the channel siltation due to typhoon.

\section{ACKNOWLEDGEMENTS}

This study is subsidized by National High Technology Research and Development Program 863 of China (2012AA112509) and Central Public Welfare Research Institutes for Basic Research Funds (TKS130106).

\section{REFERENCES}

1. Dou G. R., Dong F. W., Dou X. B., Sediment transport capacity of tidal currents and waves Chinese Bulletin of Science, Vol. 40, no.13, pp. 1096-1101, 1995.

2. Fujita T., Pressure distribution in typhoon. Geophy Mag, Vol. 23, pp. 437-452, 1952.

3. LI M. G., The effect of reclamation in areas between islands in a complex tidal estuary on the hydrodynamic sediment environment. Journal of Hydrodynamics, Vol. 22, no.3, pp. 338-350, 2010.

4. NOAA, Meteorological criteria for standard project hurricane and probable maximum hurricane wind fields, Gulf and East Coasts of the United States, National Oceanic and Atmospheric Administration, 1979.

5. Ueno T., Non-Linear numerical studies on tides and surges in the central part of Seto Inland Sea. Oceanographical Mag, Vol. 16, no.2, pp. 53-124, 1964.

6. ZHAO D. Z., LIU J, WU H. L., Preliminary analysis of typhoon-induced sudden sedimentation in navigation channel in Yangtze Estuary over last decade. Journal of Sediment Research, Vol. 4, no.2, pp. 54-60, 2012.
7. ZUO L. Q., Further study on back silting and regulation of mouth bar in Oujing esturary. Hydro-science and engineering, Vol. 3, pp. 6-13, 2012.

\section{CONTACT WITH AUTHOR}

\author{
Hongbo Zhao \\ thskzhaohongbo@163.com
}

Qinghe Zhang

School of Civil Engineering, Tianjin University 300072 Tianjin

China

\section{Hongbo Zhao \\ Mingxiao Xie}

Tianjin Research Institute for Water Transport Engineering,

Key Laboratory of Engineering Sediment of Ministry of Transport, 300456 Tianjin

China 